\title{
Analysis of Very Fast Transients in Layer-Type Transformer Windings
}

\author{
Marjan Popov, Senior Member, IEEE, Lou van der Sluis, René Peter Paul Smeets, Senior Member, IEEE, and
} Jose Lopez Roldan, Senior Member, IEEE

\begin{abstract}
This paper deals with the measurement, modeling, and simulation of very fast transient overvoltages in layer-type distribution transformer windings. Measurements were performed by applying a step impulse with 50-ns rise time on a single-phase test transformer equipped with measuring points along the winding. Voltages along the transformer windings were computed by applying multiconductor transmission-line theory for transformer layers and turns. Interturn voltage analysis has also been performed. Computations are performed by applying an inductance matrix determined in two different ways; by making use of the inverse capacitance matrix and by making use of the well known Maxwell formulas. The modeling of the transformer and the computations are verified by measurements.
\end{abstract}

Index Terms-Fourier analysis, high-frequency model, interturn voltages, transformer, very fast transients.

\section{INTRODUCTION}

$\mathbf{T}$ HE problem of very fast transient overvoltages has been widely studied and many publications have appeared on the behavior of the electrical components at high and very high frequencies [1]-[12]. Also, several CIGRE working groups and two IEEE working groups (Switchgear Committee and Transformer Committee) that deal with the problem of fast transients addressed the subject [13] and pointed out that it was sometimes difficult to identify specific transformer failures related to fast transients. The short rise time of a surge prompted by a lightning or a switching impulse can cause deterioration in the insulation and ultimately lead to a dielectric breakdown. The severity of this process depends on several factors, such as the frequency at which the transformer is exposed to this type of surge, the system configuration, the specific application of the component etc. Large power transformers are exposed to very fast transient overvoltages (VFTOs) by atmospheric discharges or gas-insulated substation (GIS) switching. Distribution transformers and motors are exposed to fast surges if they are switched by circuit

Manuscript received November 29, 2005; revised April 12, 2006. This work was supported by the Dutch Scientific Foundation NWO-STW under Grant VENI, DET.6526. Paper no. TPWRD-00679-2005.

M. Popov and L. van der Sluis are with the Power Systems Laboratory, Delft University of Technology, Delft 2628CD, The Netherlands (e-mail: M.Popov@ieee.org; L.vanderSluis@ewi.tudelft.nl).

R. P. P. Smeets is with KEMA T\&D Testing, Arnhem 6812 AR, The Netherlands, and also with the Department of Electrical Engineering, Eindhoven University of Technology, Eindhoven 5612 AZ, The Netherlands (e-mail: Rene. Smeets@kema.com).

J. Lopez Roldan is with Pauwels Trafo Belgium N.V., Mechelen B-2800,

Belgium (e-mail: jose.lopez-roldan@pauwels.com).

Digital Object Identifier 10.1109/TPWRD.2006.881605 breakers (CBs). The occurrence of VFTO in a large shell-type transformer was reported in [8] and [9], where it was demonstrated that internal resonances occur and that interturn voltages can rise to such a high value that an insulation breakdown can take place. Multiple reignitions can occur during the switching of transformers and motors with vacuum CBs (VCBs), because of the ability of VCBs to interrupt high-frequency currents. The development process of multiple reignitions has been traced in detail [14], [15]. It has been shown that the problem is not caused by the VCB or the transformer, but by an interaction of both [10]. It is therefore imperative to ascertain the speed at which transient oscillations propagate inside the windings and the coils and to identify the possible reason for a potential transformer failure.

In order to study the propagation of transients, a model is needed which is able to simulate the voltage distribution along the transformer winding. In [1]-[4], techniques of lumped parameter models are presented. Recent publications have revealed that the type of transformer winding is important for the choice of transformer model. In [8], it was demonstrated that a hybrid model based on multiconductor transmission-line theory could be successfully applied to describe the wave propagation in large shell-type transformers. In [11] and [12], two types of models were presented for transformers with interleaved windings; one was based on multiconductor transmission-line theory, while another was based on coupled inductances and capacitances. The last one uses a modified modal approach that is described in [7]. The advantage of the latter model is that it lends itself to the use of existing simulation software such as the Electromagnetic Transients Program (EMTP). Models based on multiconductor transmission-line theory can be applied if frequency analysis is used. This model is purely numerical and the losses and proximity effects, normally represented in a wide frequency range can be easily taken into account.

New developments in EMTP and Matlab have opened up possibilities for simulating very large circuits of coupled elements. The disadvantage is that resistances must be constant with the frequency. Usually, they are estimated for a constant frequency so that they give the same power factor for an $R-L$ circuit with constant resistance $R$ compared with an $R-L$ circuit where $R$ is frequency dependent [16].

This disadvantage is precluded when frequency analysis is used. The resistance can be calculated for each frequency. However, the drawback of frequency analysis is the high order of the inductance and capacitance matrices that describe the transformer coils. Apart from that, the inverse Fourier transform is normally conducted at discrete frequencies by applying 
fast Fourier transform (FFT) analysis. An accurate inversion to time domain is achieved by applying a continuous inverse Fourier transform. This generally requires long computation time or may even be unrealizable because of the large frequency spectrum, which requires operation with very large matrices.

The transmission-line theory has been reported as efficient for the analysis of transients in motor windings [17]-[19].

This paper presents a model based on multiconductor transmission-line theory for a 15-kVA single-phase test transformer with layer-type windings. The results of the voltage transients computed at the end of the first and the second layer were compared with laboratory measurements. The method is also applied for the analysis of the interturn voltages.

\section{Model for Determination of THE Line-End Voltages ON THE High-VOLTAGE WINDING}

The origin of multiconductor transmission-line modeling (MTLM) is described through the theory of natural modes in [11] and [20]. When a network of $N$ coupled lines exists, and when $\underline{Z}$ and $\underline{Y}$ are the impedance and admittance matrices, which are the self and mutual impedances and admittances between the lines, then

$$
\begin{aligned}
& \frac{d^{2} \underline{V}}{d x^{2}}=-\underline{Z Y V} \\
& \frac{d^{2} \underline{I}}{d x^{2}}=-\underline{Y Z I}
\end{aligned}
$$

where $V$ and $I$ are incident voltage and current vectors of the line. Note that $\underline{Z} \neq \underline{Y}^{-1}$. Applying the modal analysis, the system can be represented by the following two-port network:

$$
\left[\begin{array}{l}
\underline{I}_{S} \\
\underline{I}_{R}
\end{array}\right]=\left[\begin{array}{cc}
A & -B \\
-B & A
\end{array}\right]\left[\begin{array}{l}
\underline{V}_{S} \\
\underline{V}_{R}
\end{array}\right]
$$

where

$$
\begin{aligned}
& A=\underline{Y S} \underline{\gamma}^{-1} \operatorname{coth}(\underline{\gamma} l) \underline{S}^{-1} \\
& B=\underline{Y S} \underline{\gamma}^{-1} \operatorname{cosech}(\underline{\gamma} l) \underline{S}^{-1} .
\end{aligned}
$$

In (2) and (3)

$$
\begin{aligned}
& \underline{I}_{S}, \underline{I}_{R} \quad \text { current vectors at the sending and the } \\
& \underline{V}_{S}, \underline{V}_{R} \quad \text { voltage vectors at the sending and the } \\
& \text { receiving end of the line; }
\end{aligned}
$$

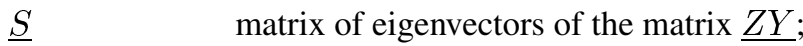

$$
\begin{aligned}
& \gamma^{2} \quad \text { eigenvalues of the matrix } Z Y \text {; } \\
& \bar{l} \quad \text { length of the line. }
\end{aligned}
$$

The system representation in (2) was applied for the computation of transients in transformer windings.

Distribution transformers are normally constructed with a large number of turns, and it would be ideal to compute voltages in every turn by representing each turn as a separate line. This implies that the model has to operate with matrices that contain a huge number of elements, which is too large to

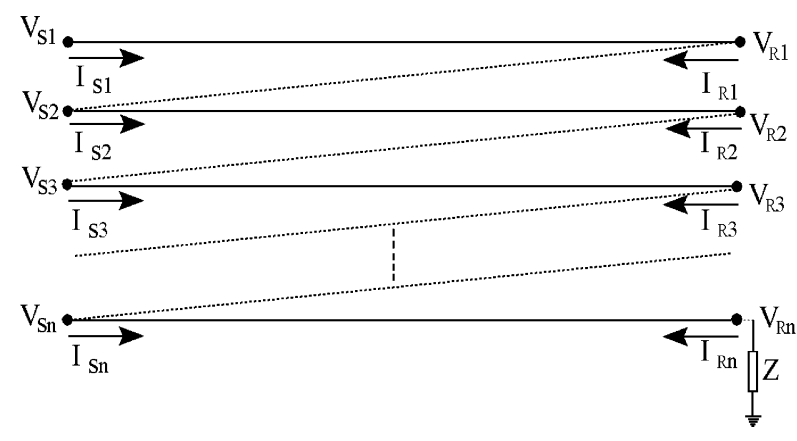

Fig. 1. Windings or turns represented by transmission lines.

be stored in the average memory of presently available desktop computers. A practical solution is to reduce the order of the matrices. This can be achieved by grouping a number of turns as a single line so that the information at the end of the line remains unchanged, as in the case when separate lines are used [8], [9]. This approach is used for layer-type modeling. Fig. 1 shows the representation of the windings by transmission lines.

At the end, the line is terminated by impedance $Z$. This means that only a group of turns can be examined and the other turns of the transformer winding can be represented by equivalent impedance. As the equivalent impedance has a significant influence, it must be calculated accurately for each frequency. In [17], a method is proposed for estimating this impedance accurately. Hybrid modeling gives a good approximation for layer-type windings. The transformer is therefore modeled on a layer-to-layer basis instead of a turn-to-turn basis. Applying (2) to Fig. 1 results in the following equation:

$$
\left[\begin{array}{l}
\underline{I}_{S 1} \\
\underline{\underline{I}}_{S 2} \\
\vdots \\
\underline{I}_{S \mathrm{n}} \\
\underline{\underline{I}}_{R 1} \\
\underline{\underline{I}}_{R 2} \\
\vdots \\
\underline{I}_{R \mathrm{n}}
\end{array}\right]=\left[\begin{array}{cc}
A^{\prime} & -B^{\prime} \\
& \\
-B^{\prime} & A^{\prime}
\end{array}\right]\left[\begin{array}{l}
\underline{V}_{S 1} \\
\underline{V}_{S 2} \\
\vdots \\
\underline{V}_{S \mathrm{n}} \\
\underline{V}_{R 1} \\
\underline{I}_{R 2} \\
\vdots \\
\underline{V}_{R \mathrm{n}}
\end{array}\right] .
$$

In (4), $\mathrm{A}^{\prime}$ and $\mathrm{B}^{\prime}$ are square matrices of the $n$th order calculated by (3). The following equations hold for Fig. 1:

$$
\begin{aligned}
\underline{I}_{R 1} & =-\underline{I}_{S 2}, \underline{I}_{R 2}=-\underline{I}_{S 3}, \ldots,-\underline{I}_{R \mathrm{n}}=\frac{\underline{V}_{R \mathrm{n}}}{\mathrm{Z}} \\
\underline{V}_{R 1} & =\underline{V}_{S 2}, \underline{V}_{R 2}=\underline{V}_{S 3}, \cdots, \underline{V}_{R \mathrm{n}-1}=\underline{V}_{S \mathrm{n}} .
\end{aligned}
$$

By using these equations and making some matrix operations (see Appendix A), (4) can be expressed as

$$
\left[\begin{array}{l}
\underline{I}_{S 1} \\
0 \\
\vdots \\
0 \\
0
\end{array}\right]=\left[\begin{array}{ll}
F & F
\end{array}\right]\left[\begin{array}{l}
\underline{V}_{S 1} \\
\underline{V}_{S 2} \\
\vdots \\
\underline{V}_{S \mathrm{n}} \\
\underline{\underline{V}}_{R \mathrm{n}}
\end{array}\right] .
$$


When we observe the model on a layer-to-layer basis, then $V_{\mathrm{Rn}}=0$; hence, (5) can be rewritten as

$$
\left[\begin{array}{l}
\underline{V}_{S 2} \\
\underline{\underline{V}}_{S 3} \\
\vdots \\
\underline{V}_{S \mathrm{n}}
\end{array}\right]=\left[\begin{array}{c}
H_{1} \\
H_{2} \\
\vdots \\
H_{\mathrm{n}-1}
\end{array}\right]\left[\begin{array}{l}
\underline{\underline{V}} \\
0 \\
\vdots \\
0 \\
0
\end{array}\right]
$$

where

$$
H_{\mathrm{k}}=\frac{F F_{\mathrm{k}+1,1}}{F F_{1,1}}, \mathrm{k}=1,2, \ldots, \mathrm{n}-1
$$

and $F F$ is the inverse matrix of the matrix $F . H$ is a square matrix of order $(\mathrm{n}-1) \times(\mathrm{n}-1)$ that contains the $H_{k}$ values of (7). One can note that the $F(1,1)$ element in (5) is the terminal admittance of the transformer.

The voltages at the end of each layer can be calculated when the voltage at the input is known and the corresponding transfer functions are calculated. The time-domain solution results from the inverse Fourier transform

$$
V_{S \mathrm{i}}(t)=\frac{2 e^{b t}}{\pi} \int_{0}^{\Omega} \frac{\sin (\pi \omega / \Omega)}{\pi \omega / \Omega} \operatorname{real}\left\{V_{\mathrm{Si}}(b+j \omega)\right\} \cos (\omega t) d \omega
$$$$
\mathrm{i}=2,3, \ldots \text { n. }
$$

In (8), the interval $[0, \Omega]$, the smoothing constant $b$, and the step frequency length $d \omega$ must be properly chosen in order to arrive at an accurate time-domain response [20]. The modified transformation requires the input function $V_{S 1}(t)$ to be filtered by an $\exp (-b t)$ window function. To compute the voltages in separate turns, the same procedure can be applied.

\section{TEST TRANSFORMER}

\section{A. Transformer Description}

To calculate the voltage transients in transformer windings, it is important to determine the transformer parameters with higher accuracy. These parameters are the inductances, the capacitances, and the frequency-dependent losses. The modeling approach depends heavily on the transformer construction and the type of windings. The test transformer in this case is a singlephase layer-type oil transformer. Fig. 2 shows the transformer during production in the factory.

The primary transformer winding consists of layers with a certain number of turns; the secondary winding is made of foiltype layers. The transformer is equipped with special measuring points in the middle and at the end of the first layer of the transformer high-voltage side, and also at the end of the second layer. All measuring points can be reached from the outside of the transformer and measurements can be performed directly at the layers. Table I shows the transformer data.

\section{B. Determination of the Transformer Parameters}

1) Capacitance: Fig. 3 shows the capacitances that are necessary for the computation of the fast transients inside the windings.

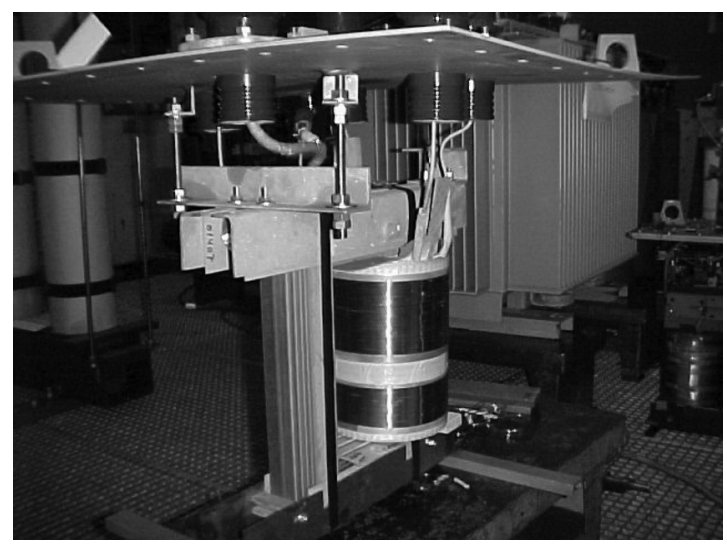

Fig. 2. Test transformer during production in the factory.

TABLE I

TRANSFORMER DATA

\begin{tabular}{|l|c|}
\hline \hline Transformer Power & $15 \mathrm{kVA}$ \\
\hline Transformer ratio & $6600 \mathrm{~V} / 69 \mathrm{~V}$ \\
\hline Short circuit voltage & $310.3 \mathrm{~V}$ \\
\hline Short circuit losses & $332.5 \mathrm{~W}$ \\
\hline No-load losses & $57.2 \mathrm{~W}$ \\
\hline No-load current & $37.3 \mathrm{~mA}$ \\
\hline Number of layers (HV side) & 15 \\
\hline Number of turns in a layer & $\sim 200$ \\
\hline Inner radius of HV winding & $73.3 \mathrm{~mm}$ \\
\hline External radius of HV winding & $97.4 \mathrm{~mm}$ \\
\hline Inner radius of the LV winding & $51 \mathrm{~mm}$ \\
\hline External radius of LV winding & $67.8 \mathrm{~mm}$ \\
\hline Wire diameter & $1.16 \mathrm{~mm}$ \\
\hline Double wire insulation & $0.09 \mathrm{~mm}$ \\
\hline Distance between layers & $0.182 \mathrm{~mm}$ \\
\hline Coil's height & $250 \mathrm{~mm}$ \\
\hline Top / bottom distance from the core & $10 \mathrm{~mm}$ \\
\hline Dielectric Permittivity of oil & 2.3 \\
\hline Dielectric Permittivity of wire insulation & 4 \\
\hline \hline
\end{tabular}

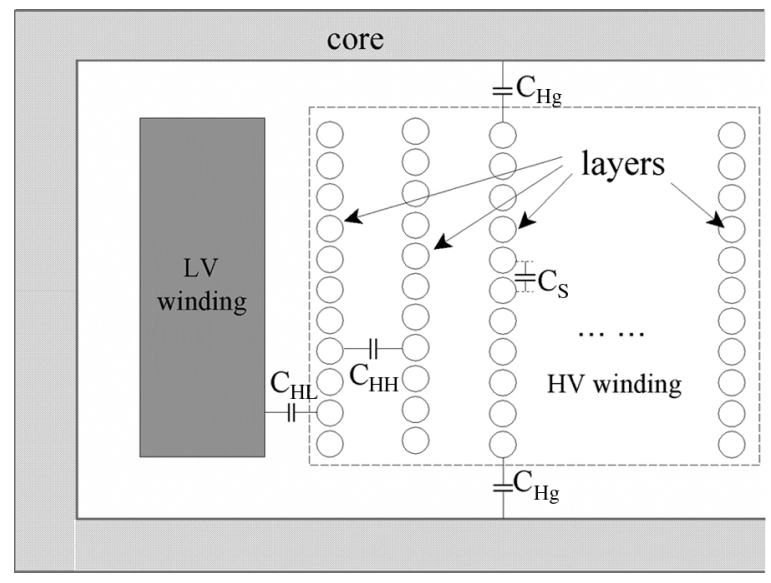

Fig. 3. Description of the capacitances inside a transformer.

These were calculated by using the basic formulas for plate and cylindrical capacitors. This is allowed because the layers and turns are so close to each other that the influence of the edges is negligible.

The capacitances $\mathrm{C}_{S}$ between the turns are important for the computation of transients in the turns. However, since the very 


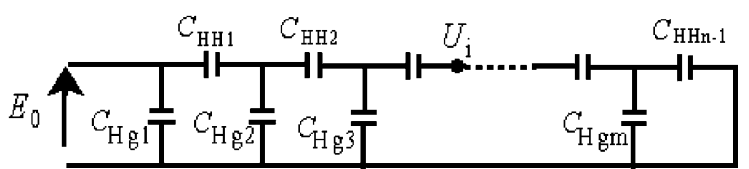

Fig. 4. Network for layer-to-layer static voltage distribution.

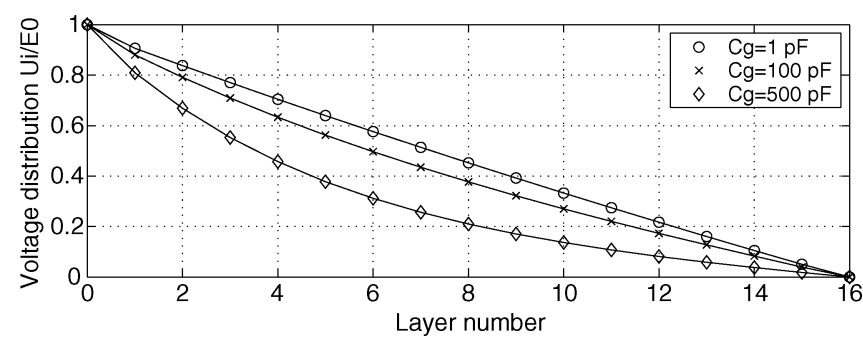

Fig. 5. Computed static voltage distribution for different grounding capacitances.

large dimensions of the matrix prevent the voltages in each turn from being solved at one and the same time, a matrix reduction can be applied [21], [22] so that the order of matrices corresponds not to a single turn but to a group of turns. In this way, the voltages at the end of the observed group of turns remain unchanged. Later, these voltages can be used for the computation of the voltage transients inside a group of turns. Capacitances $\mathrm{C}_{\mathrm{HH}}$ between layers and capacitance $\mathrm{C}_{\mathrm{HL}}$ between the primary and the secondary winding were calculated straightforwardly by treating the layers as a cylindrical capacitor.

The capacitances $\mathrm{C}_{\mathrm{Hg}}$ to the ground are small in this case and are estimated at less than $1 \mathrm{pF}$. These are the capacitances from the layers to the core. We can see in Fig. 2 that only a part of the surface of the layers is at a short distance from the core and that it is mostly the geometry of the surface that influences the value of $\mathrm{C}_{\mathrm{Hg}}$. This is explained in Appendix B. Another method is based on the extension of the width of the layer halfway into the barrier on either side of the layer [4]. The capacitances to ground are the capacitances that govern the static voltage distribution.

Fig. 5 shows the calculated static voltage distribution of each layer for a unit input voltage. When the ground capacitance is between 1 and $100 \mathrm{pF}$, the voltage distribution is more or less linear.

The equivalent input capacitance in Fig. 4 is approximately the same as the terminal phase-to-ground capacitance. The fact that the ground capacitances have a small value means that the phase-to-ground capacitance at the high-voltage side can be calculated as a series connection of the interlayer capacitances $\mathrm{C}_{\mathrm{HH}}$. Table II shows the calculated interlayer capacitances. The equivalent value that results from these capacitances is 1.21 $\mathrm{nF}$. The value of the phase-to-ground capacitance at the highvoltage side is measured in two ways. An average value of 1.25 $\mathrm{nF}$ is measured by an impedance analyzer. The other method is the voltage divider method described in [23]. The transformer high-voltage winding is connected in series with a capacitor of a known capacitance. A square impulse voltage is injected at the input and the voltage is measured at both sides. The transformer phase-to-ground capacitance is determined with a voltage division formula. Applying this method, an average value of $1.14 \mathrm{nF}$ was measured.
TABLE II

LAYER-TO-LAYER CAPACITANCE $\left(\cdot 10^{-7} \mathrm{~F}\right)$

\begin{tabular}{|l|l|l|l|}
\hline \hline & & $\mathrm{C}_{\mathrm{HH} 8}$ & 0.1729924 \\
\hline $\mathrm{C}_{\mathrm{HH} 1}$ & 0.15249997 & $\mathrm{C}_{\mathrm{HH} 9}$ & 0.1759199 \\
\hline $\mathrm{C}_{\mathrm{HH} 2}$ & 0.15542747 & $\mathrm{C}_{\mathrm{HH} 10}$ & 0.1788474 \\
\hline $\mathrm{C}_{\mathrm{HH} 3}$ & 0.15835498 & $\mathrm{C}_{\mathrm{HH} 11}$ & 0.1817749 \\
\hline $\mathrm{C}_{\mathrm{HH} 4}$ & 0.16128248 & $\mathrm{C}_{\mathrm{HH} 12}$ & 0.1847025 \\
\hline $\mathrm{C}_{\mathrm{HH} 5}$ & 0.16420998 & $\mathrm{C}_{\mathrm{HH} 13}$ & 0.1876300 \\
\hline $\mathrm{C}_{\mathrm{HH} 6}$ & 0.16713748 & $\mathrm{C}_{\mathrm{HH} 14}$ & 0.1905575 \\
\hline $\mathrm{C}_{\mathrm{HH} 7}$ & 0.17006499 & $\mathrm{C}_{\mathrm{HL}}$ & 0.00362 \\
\hline \hline
\end{tabular}

The capacitances matrix $\mathbf{C}$ was formed as follows:

$C_{i, i} \quad$ capacitance of layer $i$ to ground and the sum of all other capacitances connected to layer $i$;

$C_{i, j} \quad$ capacitance between layers $i$ and $j$ taken with the negative sign $(i \neq j)$.

The capacitance matrix has the diagonal, upper diagonal, and lower diagonal elements nonzero values and all other elements are zeros.

Dividing these values with the length of a turn, the capacitance per-unit length can be calculated.

2) Inductances: The easiest way to determine the inductance matrix $\mathbf{L}$ is to calculate the elements from the capacitance matrix C

$$
\mathbf{L}=\frac{\mathbf{C}^{-1}}{v_{s}^{2}} N^{2} \cdot \underline{l}_{\text {turn }}
$$

where the velocity of the wave propagation $v_{s}$ is calculated by

$$
v_{s}=\frac{c}{\sqrt{\varepsilon_{r}}} .
$$

and $c$ and $\varepsilon_{r}$ are the speed of light in vacuum and the equivalent dielectric constant of the transformer insulation, and $\mathrm{N}$ is the number of turns in a layer. Matrix $\mathbf{L}$ that results from (9) should be multiplied by the vector $\underline{l}_{\text {turn }}$, the elements of which are squares of the lengths of the turns in all layers. We have to point out that if matrices $\mathbf{L}$ and $\mathbf{C}$ are given in this form, then the length of the turn in (3) should be set to one. When using telegraphists equations, it is a common practice to represent the matrices $\mathbf{L}$ and $\mathbf{C}$ with their distributed parameters. Therefore, when the capacitance matrix $\mathbf{C}$ contains the distributed capacitances of the layers, the vector $\underline{l}_{\text {turn }}$ in (9) should be omitted. But regarding the reduction of the order of matrices and applying other formulas for computation of inductances, which are more convenient to calculate the inductances in $[\mathrm{H}]$ and not in $[\mathrm{H} / \mathrm{m}]$, it is shown that it is not necessary to represent the parameters with their distributed values.

Equation (9) is justified for very fast transients when the flux does not penetrate into the core, and when only the first a few microseconds are observed [17], [24]. The inductances can also be calculated by using the basic formulas for self- and mutual inductances of the turns [22], the so-called Maxwell formulas.

For turns as represented in Fig. 6, the self-inductance can be calculated as [25]

$$
L_{i i}=\mu_{0} r_{i}\left(\ln \frac{16 r_{i}}{d}-1.75\right)
$$




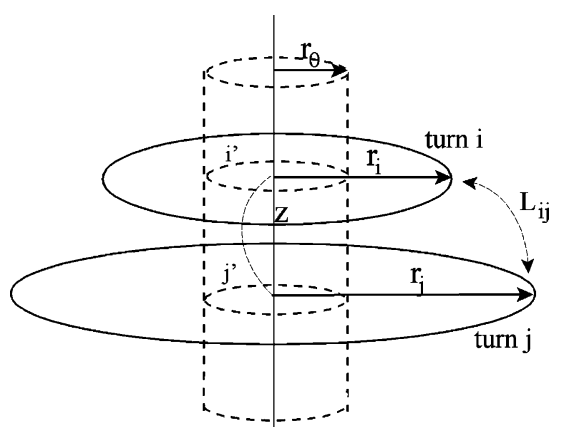

Fig. 6. Representation of circular turns for calculating inductances.

\begin{tabular}{|c|c|c|c|c|c|c|c|c|}
\hline$L_{11}$ & $L_{12}$ & $L_{13}$ & $L_{14}$ & $L_{15}$ & $L_{16}$ & \multirow{2}{*}{$\begin{array}{l}2 \times 2 \\
\sum L\end{array}$} & \multirow{2}{*}{$\begin{array}{l}2 \times 2 \\
\sum L\end{array}$} & \multirow{2}{*}{$\begin{array}{l}2 \times 2 \\
\sum L\end{array}$} \\
\hline$L_{21}$ & $L_{22}$ & $L_{23}$ & $L_{24}$ & $L_{25}$ & $L_{26}$ & & & \\
\hline$L_{31}$ & $L_{32}$ & $L_{33}$ & $L_{34}$ & $L_{35}$ & $L_{36}$ & \multirow{2}{*}{$\begin{array}{l}2 \times 2 \\
\sum L\end{array}$} & \multirow{2}{*}{$\begin{array}{l}2 \times 2 \\
\sum L\end{array}$} & \multirow{2}{*}{$\begin{array}{l}2 \times 2 \\
\sum L\end{array}$} \\
\hline$L_{41}$ & $L_{42}$ & $L_{43}$ & $L_{44}$ & $L_{45}$ & $L_{46}$ & & & \\
\hline$L_{51}$ & $L_{52}$ & $L_{53}$ & $L_{54}$ & $L_{55}$ & $L_{56}$ & \multirow{2}{*}{$\begin{array}{l}2 \times 2 \\
\sum L\end{array}$} & \multirow{2}{*}{$\begin{array}{l}2 \times 2 \\
\sum L\end{array}$} & \multirow{2}{*}{$\begin{array}{l}2 \times 2 \\
\sum L\end{array}$} \\
\hline$L_{61}$ & $L_{62}$ & $L_{63}$ & $L_{64}$ & $L_{65}$ & $L_{66}$ & & & \\
\hline
\end{tabular}

Fig. 7. Inductance matrix reduction method.

where $r_{i}$ and $d$ are the radius and the diameter of the turn. Radius $r_{i}$ is calculated as a geometrical mean distance of the turn. The mutual inductances between turns $i$ and $j$ in Fig. 6 are obtained considering the two conductors as two ring wires

$$
L_{i j}=\mu_{0} \sqrt{r_{i} r_{j}}\left(\left(\frac{2}{k}-k\right) K(k)-\frac{2}{k} E(k)\right)
$$

where $k^{2}=4 r_{i} r_{j} /\left\{\left(r_{i}+r_{j}\right)^{2}+z^{2}\right\} ; r_{i}, r_{j}$, and $z$ are the positions shown in Fig. 6; and $K(k)$ and $E(k)$ are complete elliptic integrals of the first and second kind.

In this case, it is assumed that the flux does not penetrate inside the core and a zero-flux region exists. Therefore, the obtained self- and mutual inductances are compensated

$$
L_{i i}-L_{i i^{\prime}} \text { and } L_{i j}-0.5\left(L_{i j^{\prime}}+L_{i^{\prime} j}\right) \text {. }
$$

The $i^{\prime}$ and $j^{\prime}$ are fictitious ring currents at the zero-flux region with radius $r_{0}$ with directions opposite to those of turns $i$ and $j$. The method applied here holds for inductances on a turn-to-turn basis. The large matrix can be reduced by applying a matrix reduction method based on the preservation of the same flux in the group of turns [21]. The reduction process is simply the addition of elements in the new matrix as shown in Fig. 7.

Formulas such as those published in [5], [25], and [26] can also be used. The computed matrix according to (11)-(13) is shown in the Appendix. The values of the matrix $\mathbf{L}$ computed by (9) are lower than the values computed by the accurate formulas (11)-(13). Applying (5), the frequency characteristics of the transformer can be calculated.

3) Copper and Dielectric Losses: Losses play an essential role in an accurate computation of the distributed voltages. The losses were calculated from the inductance matrix $\mathbf{L}$ and the
TABLE III

MEASURING EQUIPMENT

\begin{tabular}{|l|c|}
\hline \hline Pulse generator & $500 \mathrm{~V}$ maximum voltage \\
\hline Current probe & Pearson Electronics \\
\hline Oscilloscope & Le Croy $9304 \mathrm{~A}, 200 \mathrm{MHz}, 100 \mathrm{MS} / \mathrm{s}$ \\
\hline Voltage probes & Philips $100: 1 ; 20 \mathrm{M} \Omega / / 24 \mathrm{pF}$ \\
\hline Impedance Analyzer & $\mathrm{HP}-4194 \mathrm{~A}$ \\
\hline \hline
\end{tabular}

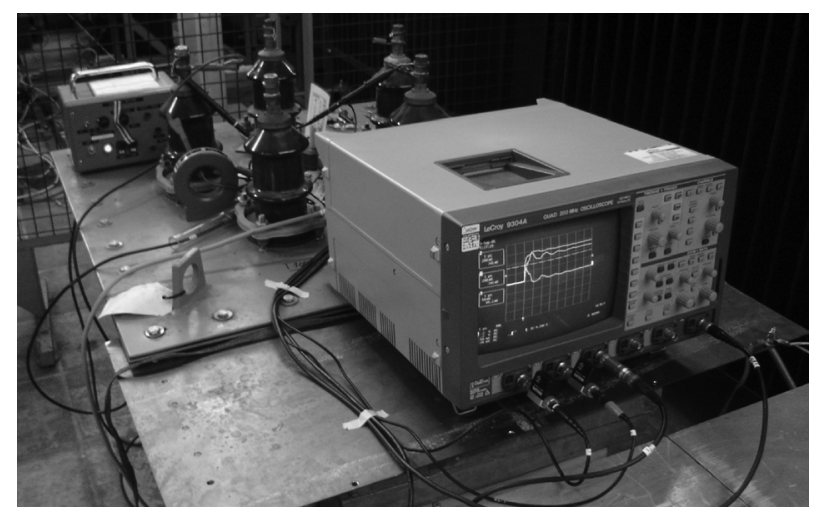

Fig. 8. Recording equipment for the measurement of fast transient oscillations.

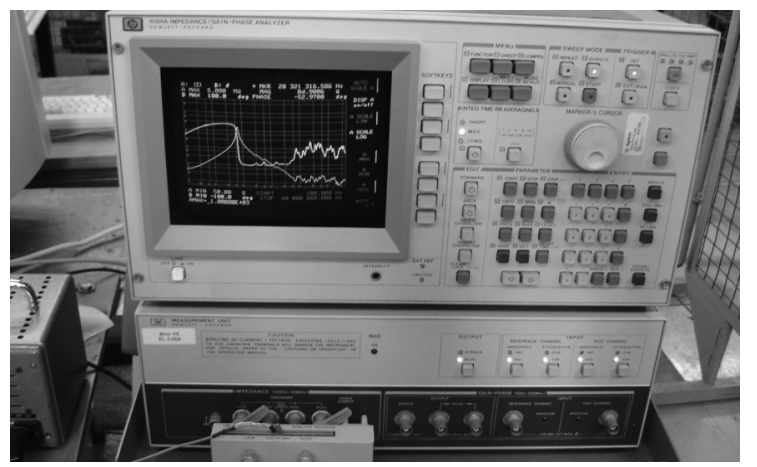

Fig. 9. Impedance analyzer for measuring the transformer impedance characteristic.

capacitance matrix $\mathbf{C}$ [12]. The impedance and admittance matrices $\underline{Z}$ and $\underline{Y}$ are then

$$
\begin{aligned}
& \underline{Z}=\left(j \omega+\sqrt{\frac{2 \omega}{\sigma \mu_{0} d^{2}}}\right) \mathbf{L} \\
& \underline{Y}=(j \omega+\omega \tan \delta) \mathbf{C} .
\end{aligned}
$$

In (14), the second term in the first equation corresponds to the Joule losses taking into account the skin effect in the copper conductor and the proximity effect. The second term in the second equation represents the dielectric losses. In (14), $d$ is the distance between layers; $\sigma$ is the conductor conductivity; and $\tan \delta$ is the loss tangent of the insulation.

\section{MEASUREMENTS AND SimUlations}

\section{A. Test Equipment}

The equipment used for measuring the fast transients in the transformer and impedance characteristics is listed in Table III. The equipment itself is shown in Figs. 8 and 9. 

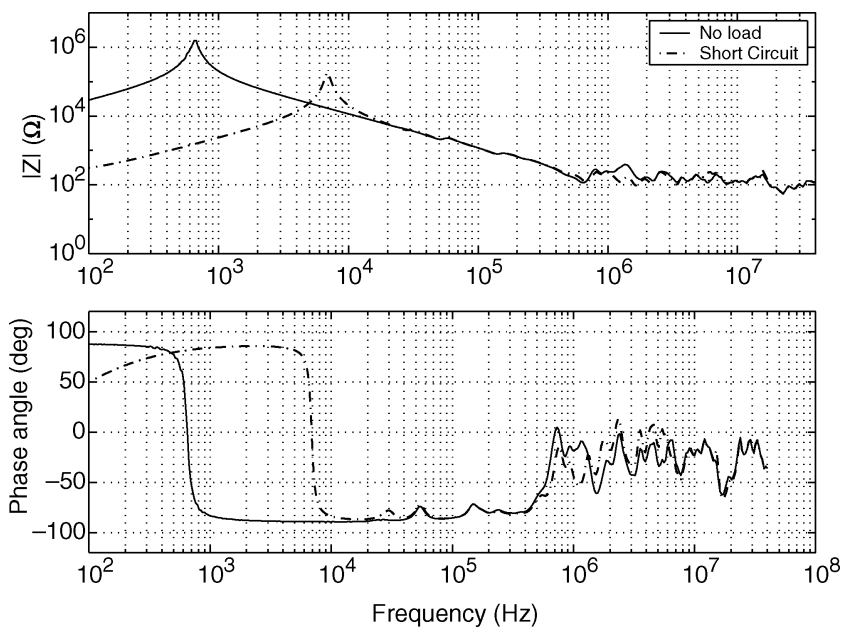

Fig. 10. Measured primary terminal impedance amplitude- and phase transformer characteristic for a transformer under no-load and for a short-circuited transformer.

The pulse generator is connected to the high-voltage transformer terminal. The source voltage is measured with a scope probe and the source current with a current probe. There is no great difference between the voltages when the low-voltage winding is short-circuited or when it is left open. The analysis was therefore carried out with only an open low-voltage winding.

\section{B. Comparison of Measured and Computed Results}

Terminal impedance characteristics on the primary and secondary side were measured for the transformer. Fig. 10 shows the amplitude and the phase terminal impedance characteristics for a no-loaded transformer and for a short-circuited transformer. This characteristic shows a resonant frequency below 1 $\mathrm{kHz}$ (during no load). This frequency is outside the scope of this paper. It can be seen that, in the case of a short-circuited transformer, the resonant frequency moves to the right and downwards.

This shows that the core has a significant influence for frequencies below $10 \mathrm{kHz}$. Above $10 \mathrm{kHz}$, the two characteristics overlap. This indicates that only a small part of the flux penetrates into the core.

Fig. 11 shows the comparison between the measured and the calculated impedance characteristics. The impedance characteristics is determined by making use of matrices obtained in two ways.

\section{Comparison of Measured and Computed Results}

The measurement setup is shown in Fig. 8. The measuring terminals are on the top of the transformer lid. We can see in Fig. 2 that the transformer windings are actually connected to the transformer terminals by conductors with different parameters from those used for the transformer windings. These conductors are brought to the top of the transformer through conductive insulators, and as it can be seen from Fig. 2, they are passing close to the transformer core. The source voltage is not equal to the voltage at the first turn. The voltages measured at
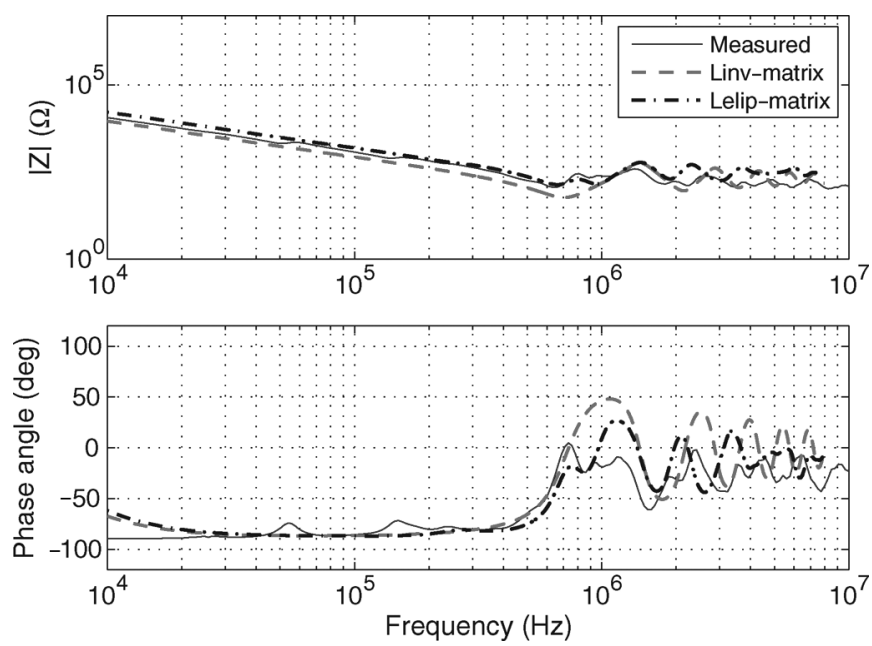

Fig. 11. Comparison between the measured and the calculated impedance characteristics.

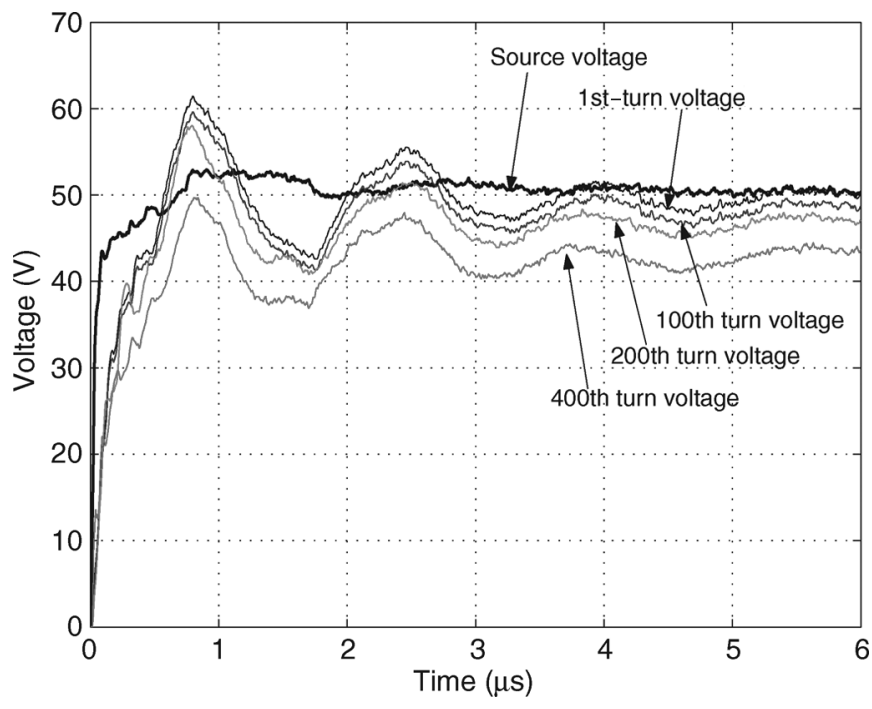

Fig. 12. Measured voltages at the available transformer taps.

the 100th, 200th, 400th turn, and the source voltage are shown in Fig. 12.

Note that the voltages measured at selected points have waveshapes that differ from the shape of the source voltage. The developed model is valid only for the high-voltage transformer winding and not for the other connections that connect the transformer winding with the measuring points. So the voltage at the first turn can therefore be estimated from Fig. 5, because the static voltage distribution is almost linear. Fig. 13 shows a comparison between the measured voltages and the calculated voltages at the end of the first and second layer that correspond to the 200th and 400th turn, respectively. In Fig. 14, a comparison between voltages calculated by different inductance matrix is presented.

\section{Interturn Voltage Analysis}

Interturn voltages can be calculated if we apply Fig. 1 that represents a group of turns under interest that are terminated by the terminal impedance. The terminal impedance will now be an equivalent for the rest of the turns in the transformer. We 


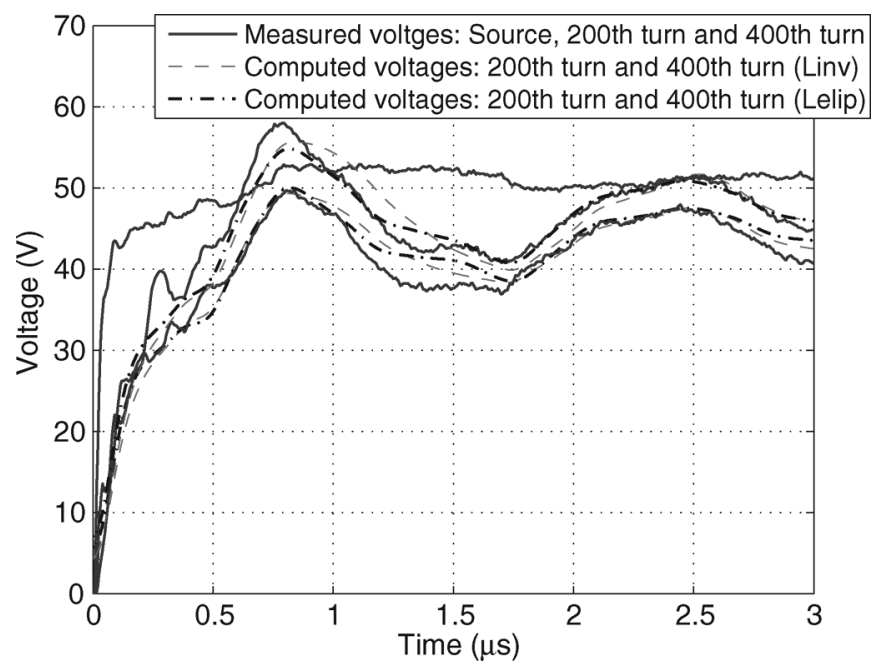

Fig. 13. Comparison between measured and computed voltage transients.

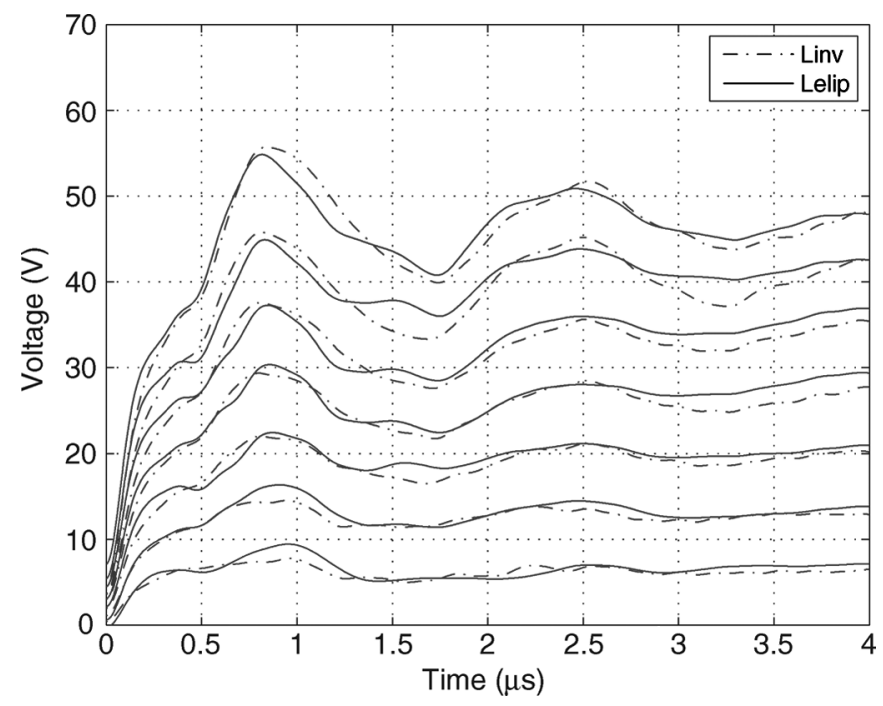

Fig. 14. Comparison between the calculated voltages at the (200th, 600th, 1000th, 1400th, 1800th, 2200th, and 2600th turn) by making use of both types of $\mathbf{L}$ matrices.

start the computation from the group of turns in the first layer. The terminal impedance is equal to the terminal impedance of the transformer calculated from Fig. 11. It is extracted from the element $F(1,1)$ from the matrix in (5).

This assumption is the most accurate to predict the terminal impedance of the rest of the turns because, the few tens of turns will not change the total transformer terminal impedance significantly. This process can be applied for the rest of the group of turns iteratively so that all turn-to-ground voltages can be determined. The $\mathbf{L}$ and $\mathbf{C}$ matrices need to be recalculated. They are calculated on the turn-to-turn bases and the same approach can be applied as described in Chapter 3. Some results of the interturn voltage analysis for the first layer are represented in Figs. 15 and 16, respectively.

\section{DISCUSSION}

The study presented here shows that transmission-line theory is suitable for representing layer-type transformers. The volt-

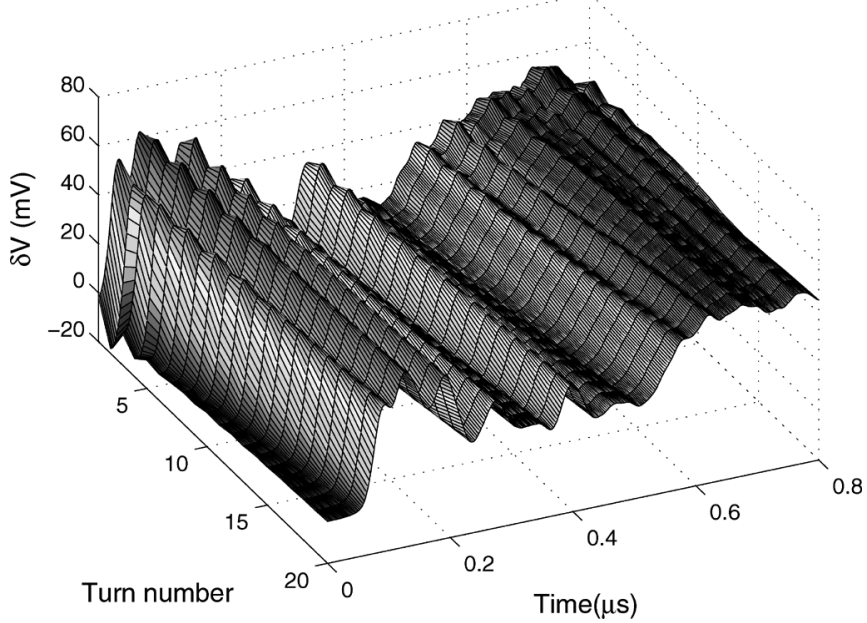

Fig. 15. Distribution of interturn voltages for the first 20 turns in the first layer.

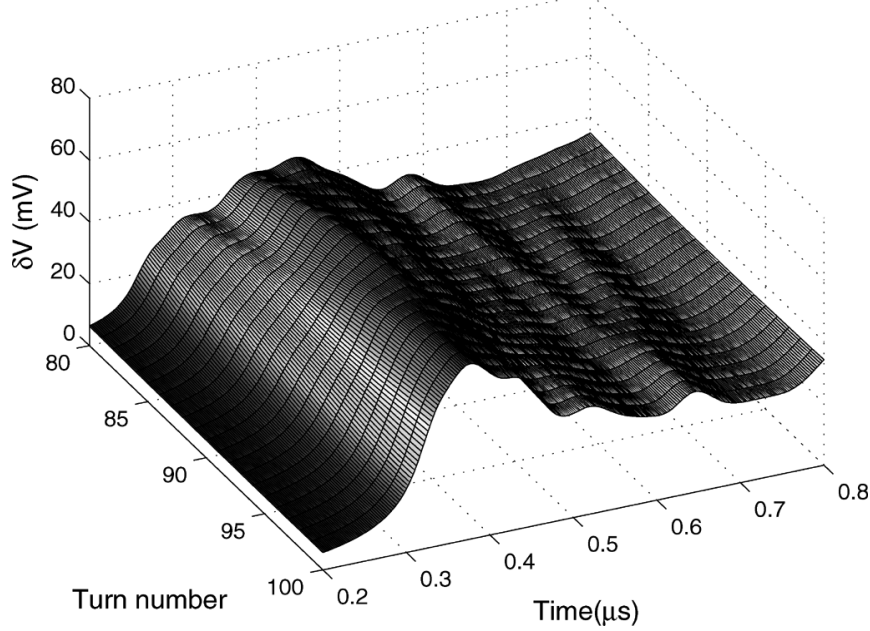

Fig. 16. Distribution of interturn voltages from the 80th through the 100th turn in the first layer.

ages at the end of the first and second layer were measured in a laboratory and simulated by applying the transmission-line theory. The voltages at the end of the other layers can be calculated in the same way. When fast surges reach the transformer terminal, interturn and interlayer insulation might suffer severe stress because of the amplitude and the steepness of the voltage transients. The measurements of the terminal impedance characteristic follow that no resonance frequencies in the high-frequency region for this particular transformer exist. Although no internal resonance was found on the high-voltage winding, for other transformers it might occur. Interturn voltage analysis shows that higher and steeper interturn voltages occur in the first layer of the transformer.

This study presents the worst-case scenario, when a steep surge is applied directly to the transformer terminal. This scenario could conceivably occur in, for instance, arc furnace systems, where the transformer is positioned close to the switchgear. When a cable is connected to the primary transformer side, the voltages will probably be less steep than in the case presented here, but this assumption needs to be further investigated. 


\section{CONCLUSION}

Modeling of layer-type distribution transformers by representing the turns and layers by transmission lines has been performed. The applied method is sufficient for computation of the voltages along the turns and layers when the inductance matrix $\mathbf{L}$ and capacitance matrix $\mathbf{C}$ are accurately determined. Inductance matrix is computed in two ways: by inversion of the $\mathbf{C}$ and by computing it on a turn-to-turn basis with the traditionally known Maxwell formulas.

In the analysis, the proximity losses are taken into account so that the $\mathbf{R}$ matrix is not diagonal. This way of representing the inductances and losses is sufficient for very fast transients up to a few microseconds. To observe transients with a longer period of time, which have oscillation with different frequencies such as restrikes in the CBs during switching transformers, the influence of the frequency-dependent core losses must be taken into account.

\section{FUTURE WORK}

Developing an equivalent lumped parameter model will be a useful challenge for the future. Additional work will be done to include the full frequency-dependent core losses.

\section{APPENDIX A}

\section{VERIFICATION OF (5)}

Equation (5) can be verified by the following approach. To simplify the proof, we will take the number of lines in Fig. 1 to be $\mathrm{n}=3$. Then, in (4) $\left.\underline{I}_{S}={ }^{[} \underline{I}_{S 1} \underline{I}_{S 2} \underline{I}_{S 3}\right]^{\mathrm{T}}$, $\underline{I}_{R}=\left[\underline{I}_{R 1} \underline{I}_{R 2} \underline{I}_{R 3}\right]^{\mathrm{T}}, \underline{V}_{S}=\left[\underline{V}_{S 1} \underline{V}_{S 2} \underline{V}_{S 3}\right]^{\mathrm{T}}$, and $\underline{V}_{R}=\left[\underline{V}_{R 1} \underline{V}_{R 2} \underline{V}_{R 3}\right]^{\mathrm{T}}$. If we denote that

$$
P=\left[\begin{array}{cc}
A & -B \\
-B & A
\end{array}\right]
$$

then $P$ is a square matrix of order $6 \times 6$. Applying the terminal conditions in (5), the following equations are valid:

$$
\begin{aligned}
\underline{I}_{R 1} & =-\underline{I}_{S 2}, \\
\underline{I}_{R 2} & =-\underline{I}_{S 3},-\underline{I}_{R 3} \\
& =\frac{\underline{V}_{R 3}}{\mathrm{Z}}, \\
\underline{V}_{R 1} & =\underline{V}_{S 2}, \\
\underline{V}_{R 2} & =\underline{V}_{S 3}
\end{aligned}
$$

and in order to simplify (4), (A.2) are substituted in (4). If we add columns four to two, and five to three without altering the system equations, then (4) becomes

$$
\left[\begin{array}{l}
\underline{I}_{S} \\
\underline{I}_{R}
\end{array}\right]=P_{1}\left[\begin{array}{c}
\underline{V}_{S} \\
\underline{V}_{R 3}
\end{array}\right] .
$$

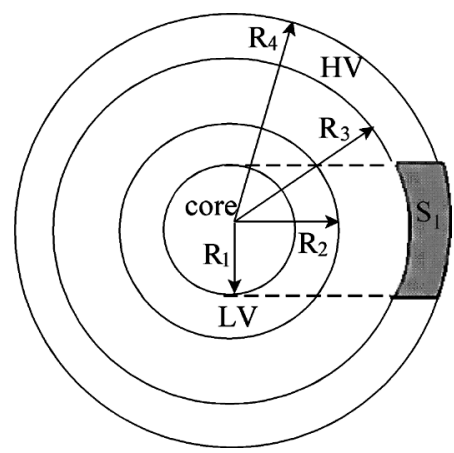

Fig. 17. Part of the HV winding surface which is located at the nearest distance from the core.

By substituting $\underline{I}_{S 2}$ and $\underline{I}_{S 3}$ from (A.2) in (A.3) and adding rows four to two and five to three, (A.3) becomes

$$
\left[\begin{array}{l}
\underline{I}_{S 1} \\
0 \\
0 \\
\underline{I}_{R 1} \\
\underline{I}_{R 2} \\
\underline{I}_{R 3}
\end{array}\right]=P_{2}\left[\begin{array}{l}
\frac{V}{V} S 1 \\
\underline{V}_{S 2} \\
\underline{V}_{S 3} \\
\underline{V}_{R 3}
\end{array}\right] .
$$

Rows four and five can be eliminated, so (A.4) becomes

$$
\left[\begin{array}{l}
\underline{I}_{S 1} \\
0 \\
0 \\
\underline{I}_{R 3}
\end{array}\right]=P_{3}\left[\begin{array}{l}
\underline{V}_{S 1} \\
\underline{V}_{S 2} \\
\underline{V}_{S 3} \\
\underline{V}_{R 3}
\end{array}\right] .
$$

By substituting the terminal condition for the current $\underline{I}_{R 3}$ and rearranging (A.5), (5) can be derived.

\section{APPENDIX B}

\section{COMPUTATION OF CAPACITANCE TO GROUND}

Surface $\mathrm{S}_{1}$, as shown in Fig. 17, represents a part of the winding surface of the $\mathrm{HV}$ winding that is on the shortest distance from the core

$$
\begin{aligned}
S_{1}=R_{4}^{2} \arcsin \frac{R_{1}}{R_{4}} & +R_{1} \sqrt{R_{4}^{2}-R_{1}^{2}} \\
& -R_{3}^{2} \arcsin \frac{R_{1}}{R_{3}}-R_{1} \sqrt{R_{3}^{2}-R_{1}^{2}} .
\end{aligned}
$$

Capacitance to ground is calculated as

$$
C_{g g}=\varepsilon \varepsilon_{0} \frac{\mathrm{S}_{1}}{\mathrm{~d}_{\text {top }}}
$$

where $\varepsilon$ is the dielectric permittivity of the oil and $d_{\text {top }}$ is the distance between the surface $\mathrm{S}_{1}$ and the core. Capacitance of a layer to ground is $\mathrm{C}_{g}=\mathrm{C}_{g g} / \mathrm{N}_{\text {layer }}$.

\section{APPENDIX C}

INDUCTANCE MATRIX L (mH) ACCORDING TO (11)-(13)

See the first matrix at the bottom of the next page. 


\section{APPENDIX D \\ INDUCTANCE MATRIX L (mH) ACCORDing TO (9)}

See the second matrix at the bottom of the page.

\section{ACKNOWLEDGMENT}

The authors would like to thank Dr. J. Declercq and Ir. H. de Herdt from Pauwels Transformers. They are also indebted to Kema High Voltage Laboratories and the High Current Laboratory at Eindhoven University of Technology, Eindhoven, The Netherlands, for supplying the necessary equipment and for the use of their facilities, to Ir. R. Kerkenaar and Dr. A.P.J. van Deursen for their assistance in performing measurements of fast transients, and to Dr. J. L. Guardado from ITM, Morelia, Mexico, for acting as a discussion partner.

\section{REFERENCES}

[1] R. C. Degeneff, W. J. McNutt, W. Neugebauer, J. Panek, M. E. McCallum, and C. C. Honey, "Transformer response to system switching voltage," IEEE Trans. Power App. Syst., vol. PAS-101, no. 6, pp. 1457-1470, Jun. 1982.

[2] M. Gutierrez, R. C. Degeneff, P. J. McKenny, and J. M. Schneider, "Linear lumped parameter transformer model reduction technique," IEEE Trans. Power Del., vol. 10, no. 2, pp. 853-861, Apr. 1995.

[3] M. Gutierrez, R. C. Degeneff, and P. J. McKenny, "A method for constructing reduced order models for system studies from detailed lumped parameter models," IEEE Trans. Power Del., vol. 7, no. 2, pp. 649-655, Apr. 1992.

[4] R. C. Dugan, R. Gabrick, J. C. Wright, and K. V. Pattern, "Validated techniques for modeling shell-form EHV transformers," IEEE Trans. Power Del., vol. 4, no. 2, pp. 1070-1078, Apr. 1989.

[5] P. I. Fergestad and T. Henriksen, "Inductances for the calculation of transient oscillations in transformers," IEEE Trans. Power App. Syst., vol. PAS-93, no. 2, pp. 510-517, Mar./Apr. 1974.

[6] T. Van Craenenbroeck, J. De Ceuster, J. P. Marly, H. De Herdt, B. Brouwers, and D. Van Dommelen, "Experimental and numerical analysis of fast transient phenomena in distribution transformers," in Proc. IEEE Power Eng. Soc. Winter Meeting, Singapore, 2000, CD-ROM (6p).

$\begin{array}{lllllllllllllll}1.344 & 1.454 & 1.437 & 1.422 & 1.407 & 1.393 & 1.379 & 1.365 & 1.351 & 1.338 & 1.325 & 1.312 & 1.299 & 1.286 & 1.274 \\ 1.454 & 1.491 & 1.562 & 1.545 & 1.529 & 1.513 & 1.498 & 1.483 & 1.469 & 1.454 & 1.440 & 1.426 & 1.413 & 1.399 & 1.386 \\ 1.437 & 1.562 & 1.599 & 1.671 & 1.653 & 1.637 & 1.620 & 1.605 & 1.589 & 1.574 & 1.559 & 1.544 & 1.530 & 1.515 & 1.501 \\ 1.422 & 1.545 & 1.671 & 1.708 & 1.782 & 1.763 & 1.746 & 1.729 & 1.712 & 1.696 & 1.680 & 1.664 & 1.649 & 1.634 & 1.619 \\ 1.407 & 1.529 & 1.653 & 1.782 & 1.818 & 1.894 & 1.875 & 1.856 & 1.838 & 1.821 & 1.804 & 1.787 & 1.771 & 1.755 & 1.739 \\ 1.393 & 1.513 & 1.637 & 1.763 & 1.894 & 1.930 & 2.008 & 1.987 & 1.968 & 1.949 & 1.931 & 1.914 & 1.896 & 1.879 & 1.862 \\ 1.379 & 1.498 & 1.620 & 1.746 & 1.875 & 2.008 & 2.043 & 2.122 & 2.101 & 2.081 & 2.062 & 2.043 & 2.024 & 2.006 & 1.988 \\ 1.365 & 1.483 & 1.605 & 1.729 & 1.856 & 1.987 & 2.122 & 2.157 & 2.238 & 2.216 & 2.195 & 2.175 & 2.155 & 2.136 & 2.117 \\ 1.351 & 1.469 & 1.589 & 1.712 & 1.838 & 1.968 & 2.101 & 2.238 & 2.273 & 2.355 & 2.332 & 2.310 & 2.289 & 2.269 & 2.249 \\ 1.338 & 1.454 & 1.574 & 1.696 & 1.821 & 1.949 & 2.081 & 2.216 & 2.355 & 2.389 & 2.473 & 2.449 & 2.427 & 2.405 & 2.384 \\ 1.325 & 1.440 & 1.559 & 1.680 & 1.804 & 1.931 & 2.062 & 2.195 & 2.332 & 2.473 & 2.507 & 2.593 & 2.567 & 2.544 & 2.522 \\ 1.312 & 1.426 & 1.544 & 1.664 & 1.787 & 1.914 & 2.043 & 2.175 & 2.310 & 2.449 & 2.593 & 2.627 & 2.714 & 2.687 & 2.663 \\ 1.299 & 1.413 & 1.530 & 1.649 & 1.771 & 1.896 & 2.024 & 2.155 & 2.289 & 2.427 & 2.567 & 2.714 & 2.747 & 2.835 & 2.808 \\ 1.286 & 1.399 & 1.515 & 1.634 & 1.755 & 1.879 & 2.006 & 2.136 & 2.269 & 2.405 & 2.544 & 2.687 & 2.835 & 2.869 & 2.958 \\ 1.274 & 1.386 & 1.501 & 1.619 & 1.739 & 1.862 & 1.988 & 2.117 & 2.249 & 2.384 & 2.522 & 2.663 & 2.808 & 2.958 & 2.992\end{array}$

$\begin{array}{lllllllllllllll}0.951 & 0.985 & 1.019 & 1.054 & 1.090 & 1.126 & 1.163 & 1.201 & 1.240 & 1.280 & 1.321 & 1.362 & 1.405 & 1.448 & 1.493 \\ 0.948 & 1.008 & 1.043 & 1.079 & 1.116 & 1.153 & 1.191 & 1.230 & 1.270 & 1.311 & 1.353 & 1.395 & 1.439 & 1.483 & 1.528 \\ 0.945 & 1.005 & 1.068 & 1.104 & 1.142 & 1.180 & 1.219 & 1.259 & 1.300 & 1.341 & 1.384 & 1.427 & 1.472 & 1.517 & 1.564 \\ 0.943 & 1.003 & 1.065 & 1.129 & 1.167 & 1.206 & 1.246 & 1.287 & 1.329 & 1.371 & 1.415 & 1.459 & 1.505 & 1.551 & 1.599 \\ 0.941 & 1.000 & 1.062 & 1.126 & 1.193 & 1.233 & 1.273 & 1.315 & 1.358 & 1.401 & 1.446 & 1.491 & 1.538 & 1.585 & 1.634 \\ 0.938 & 0.998 & 1.060 & 1.124 & 1.190 & 1.259 & 1.300 & 1.343 & 1.386 & 1.431 & 1.476 & 1.523 & 1.570 & 1.619 & 1.668 \\ 0.937 & 0.996 & 1.058 & 1.121 & 1.188 & 1.256 & 1.327 & 1.371 & 1.415 & 1.460 & 1.507 & 1.554 & 1.603 & 1.652 & 1.703 \\ 0.935 & 0.994 & 1.056 & 1.120 & 1.186 & 1.254 & 1.325 & 1.398 & 1.443 & 1.490 & 1.537 & 1.585 & 1.635 & 1.685 & 1.737 \\ 0.934 & 0.993 & 1.054 & 1.118 & 1.184 & 1.252 & 1.323 & 1.396 & 1.471 & 1.519 & 1.567 & 1.616 & 1.667 & 1.718 & 1.771 \\ 0.932 & 0.992 & 1.053 & 1.116 & 1.182 & 1.251 & 1.321 & 1.394 & 1.470 & 1.548 & 1.597 & 1.647 & 1.698 & 1.751 & 1.804 \\ 0.931 & 0.991 & 1.052 & 1.115 & 1.181 & 1.249 & 1.320 & 1.393 & 1.468 & 1.546 & 1.626 & 1.678 & 1.730 & 1.783 & 1.838 \\ 0.931 & 0.990 & 1.051 & 1.114 & 1.180 & 1.248 & 1.319 & 1.392 & 1.467 & 1.545 & 1.625 & 1.708 & 1.761 & 1.816 & 1.871 \\ 0.930 & 0.989 & 1.050 & 1.114 & 1.179 & 1.247 & 1.318 & 1.391 & 1.466 & 1.544 & 1.624 & 1.707 & 1.792 & 1.848 & 1.904 \\ 0.930 & 0.989 & 1.050 & 1.113 & 1.179 & 1.247 & 1.317 & 1.390 & 1.465 & 1.543 & 1.623 & 1.706 & 1.792 & 1.880 & 1.937 \\ 0.930 & 0.989 & 1.050 & 1.113 & 1.179 & 1.247 & 1.317 & 1.390 & 1.465 & 1.543 & 1.623 & 1.706 & 1.791 & 1.879 & 1.970\end{array}$


[7] D. J. Wilcox, W. G. Hurleay, T. P. McHale, and M. Conion, "Application of modified modal theory in the modeling of practical transformers," Proc. Inst. Elect. Eng. C, vol. 139, no. 6, pp. 513-520, 1992.

[8] Y. Shibuya, S. Fujita, and N. Hosokawa, "Analysis of very fast transient overvoltages in transformer winding," Proc. Inst. Elect. Eng., Gen., Transm. Distrib., vol. 144, no. 5, pp. 461-468, Sep. 1997.

[9] M. Popov, L. van der Sluis, G. C. Paap, and H. de Herdt, "Computation of very fast transient overvoltages in transformer windings," IEEE Trans. Power Del., vol. 18, no. 4, pp. 1268-1274, Oct. 2003.

[10] J. Lopez-Roldan, H. de Herdt, T. Sels, D. van Dommelen, M. Popov, L. van der Sluis, and J. Declercq, "Analysis, simulation and testing of transformer insulation failures related to switching transients overvoltages," presented at the CIGRE, Paris, France, 2002, paper 12-116, unpublished.

[11] K. J. Cornick, B. Fillat, C. Kieny, and W. Müller, "Distribution of very fast transient overvoltages in transformer windings," presented at the CIGRE, Paris, France, 1992, paper 12-204, unpublished.

[12] Y. Shibuya and S. Fujita, "High frequency model of transformer winding," Elect. Eng. Jpn., vol. 146, no. 3, pp. 8-15, 2004.

[13] CIGRE SC A3, "Electrical environment of transformers-impact of fast transients," Summary Paper of the, CIGRE JWG 12/32/23.21, A3-04 (SC) 26 IWD.

[14] M. Popov, L. van der Sluis, and G. C. Paap, "Investigation of the circuit breaker reignition overvoltages caused by no-load transformer switching surges," Eur. Trans. Elect. Power, vol. 11, no. 6, pp. 413-422, Nov./Dec. 2001.

[15] M. Popov and L. van der Sluis, "Improved calculations for no-load transformer switching surges," IEEE Trans. Power Del., vol. 16, no. 3, pp. 401-408, Jul. 2001.

[16] Y. Shibuya, T. Matsumoto, and T. Teranishi, "Modeling and analysis of transformer winding at high frequencies," presented at the Int. Conf. Power Systems Transients , Montreal, QC, Canada, Jun. 19-23, 2005, Paper no. IPST05-025, unpublished.

[17] J. L. Guardado and K. J. Cornick, "A computer model for calculating steep-fronted surge distribution in machine windings," IEEE Trans. Energy Convers., vol. 4, no. 1, pp. 95-101, Mar. 1989.

[18] R. E. Adjaye and K. J. Cornick, "Distribution of switching surges in the line-end coils of cable connected motors," Proc. Inst. Elect. Eng., Elect. Power Appl., vol. 2, no. 1, pp. 11-21, Feb. 1979.

[19] P. G. McLaren and H. Oraee, "Multiconductor transmission-line model for the line-end coil of large AC machines," Proc. Inst. Elect. Eng. B, vol. 132, no. 3, pp. 149-156, May 1985.

[20] J. P. Bickford, N. Mullineux, and J. R. Reed, Computation of Power System Transients. London, U.K.: Peregrinus, 1976, 0901223859.

[21] F. de Leon and A. Semlyen, "Reduced order model for transformer transients," IEEE Trans. Power Del., vol. 7, no. 1, pp. 361-369, Jan. 1992.

[22] - "Efficient calculation of elementary parameters of transformers," IEEE Trans. Power Del., vol. 7, no. 1, pp. 376-383, Jan. 1992.

[23] J. Mikulovic, "Modeling of wave propagation in transformer windings by means of state equations," (in Serbian) M.Sc. thesis, Faculty Elect. Eng., Univ. Belgrade, Belgrade, Yugoslavia, Mar. 1999.

[24] J. L. Guardado and K. J. Cornick, "Calculation of machine winding electrical parameters at high frequencies for switching transients studies," IEEE Trans. Energy Convers., vol. 11, no. 1, pp. 33-40, Mar. 1996.

[25] F. Grover, Inductance Calculation: Working Formulas and Tables. New York: Dover, 1946, 0-87664-557-0.

[26] K. A. Wirgau, "Inductance calculation of an air core winding," IEEE Trans. Power App. Syst., vol. PAS-95, no. 1, pp. 394-400, Jan./Feb. 1976.

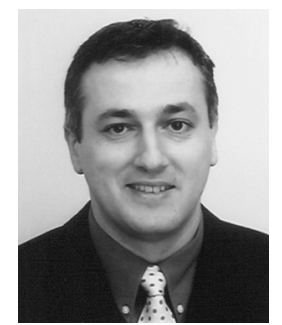

Marjan Popov (M'95-SM'03) received the Dipl.-Ing. and M.S. degrees in electrical engineering from the Sts. Cyril and Methodius University, Skopje, Macedonia, in 1993 and 1998, respectively, and the Ph.D. degree from Delft University of Technology, Delft, The Netherlands, in 2002.

From 1993 to 1998, he was a Teaching and Research Assistant with the Faculty of Electrical Engineering, University of Skopje, spending 1997 as a Visiting Researcher with the University of Liverpool, Liverpool, U.K. Currently, he is an Assistant Professor in the Electrical Power Systems Group, Power Systems Laboratory, Delft University of Technology. His research interests are in arc modeling, transients in power systems, parameter estimation, and relay protection.

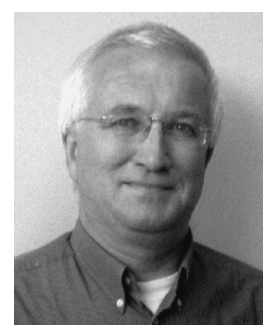

Lou van der Sluis was born in Geervliet, The Netherlands, on July 10, 1950. He received the M.Sc. degree in electrical engineering from the Delft University of Technology, Delft, The Netherlands, in 1974.

He joined the KEMA High Power Laboratory in 1977 as a Test Engineer and was involved in the development of a data-acquisition system for the High Power Laboratory, computer calculations of test circuits, and the analysis of test data by digital computers. He became a Part-Time Professor in 1990 and, two years later, was appointed Full-Time Professor with the Power Systems Department at Delft University of Technology.

Prof. van der Sluis is a former Chairman of CC-03 of CIGRE and CIRED to study the transient recovery voltages in medium- and high-voltage networks. $\mathrm{He}$ is a member of CIGRE Working Group A3-20 for modeling power systems components.

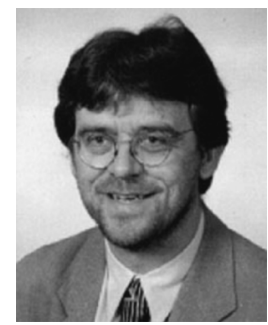

René Peter Paul Smeets (M'95-SM'02) received the M.Sc. degree in physics and the Ph.D. degree for research on vacuum arcs from Eindhoven University of Technology, Eindhoven, The Netherlands, in 1981 and 1987, respectively.

He was an Assistant Professor with Eindhoven University of Technology until 1995. In 1991, he was with Toshiba Corporation's Heavy Apparatus Engineering Laboratory, Kawasaki, Japan, and, in 1995, joined KEMA, Arnhem, The Netherlands. He manages the R\&D activities of KEMA's High Power Laboratory. In 2001, he was appointed Part-Time Professor at the Eindhoven University of Technology.

Jose Lopez Roldan (M'97-SM'05) was born in San Sebastian, Spain, in 1966. He received the M.Sc. and Ph.D. degrees in electrical engineering from the University of Barcelona, Barcelona, Spain, in 1993 and 1997, respectively.

He was a Visiting Researcher with the R\&D Centers of Ontario-Hydro, Toronto, ON, Canada; Schneider-Electric, Grenoble, France; and EDF, Paris, France, where he worked on electrical insulation of high-voltage equipment. From 1996 to 2000, he was a Senior Engineer with VA TECH-Reyrolle, Hebburn, U.K., engaged in the development of high-voltage gas-insulated switchgear. He was R\&D Project Manager with the Transformer Division with Trafo Belgium, Mechelen, Belgium, in 2000 and since 2002, has been Engineering Manager with the Projects Division, where he is responsible for the engineering of substations.

Dr. Roldan is a member of CIGRE. 